\title{
PERIPHERAL VASCULAR INJURIES AND THEIR MANAGEMENT IN ACCRA
}

\author{
${ }^{*}$ H. K. ADUFUL and W. M. HODASI \\ Department Of Surgery, University of Ghana Medical School, P.O. Box 4236, Accra, Ghana
}

\begin{abstract}
SUMMARY
Background: The true incidence of vascular injuries in Ghana is not known on account of low reporting.

Objective: We performed a study aimed at reviewing the pattern of injuries to peripheral vessels, and also the pattern of referral, presentation and management of these injuries at the Korle-Bu Teaching Hospital, Accra.

Method: The study covered the period of January 1989 to March 2005 and involved a review of all peripheral vessel injuries referred for vascular surgical opinion.

Results: Fifty two (52) patients with aged between 1350 years were reviewed. Penetrating trauma (82.7\%) and blunt trauma (11.5\%) were the commonest modes of injury. Arterial injuries (63.5\%) and combined arterial and venous injuries (23.1\%) were the commonest forms of injury. Brachial artery injuries were the commonest injuries seen. Associated nerve injuries occurred in $25 \%$ of patients most of whom also had brachial artery injuries. Late presentations of false aneurysms and arteriovenous fistulae were seen in $40.4 \%$ patients. There were delays in referring patients (range 1 hour to 4 years). Vascular investigations like angiograms and duplex scanning were obtained in only $25.0 \%$ of patients. Vascular reconstruction was successful in $84.6 \%$ patients and $7.7 \%$ of patients required major limb amputation and an equal number of patients died from other injuries.

Conclusion: There is undue delay in referring patients with vascular injuries for intervention due to the inability of the initial attending medical personnel to recognize these injuries. Most of these injuries can be adequately treated without the use of sophisticated investigations, which are usually expensive.
\end{abstract}

Key Words: Arterial injuries, venous injuries, false aneurysms, arteriovenous fistula

\section{INTRODUCTION}

Traumatic injuries to major peripheral vessels in civilian life are quite uncommon worldwide. These injuries are, however, common in certain parts of South Africa ${ }^{1,2}$ and the United States of America. ${ }^{3,4}$ Vascular trauma has also gained prominence in recent times due to interventional procedures performed on arteries and veins and such iatrogenic injuries are the commonest causes of vascular injuries in certain parts of the western world. ${ }^{5,6}$ The real incidence in Ghana and probably the rest of the West African region may not be known due to low reporting. These injuries may be neglected or missed with the result of considerable morbidity with loss of limb and mortality. Injuries to peripheral vessels are also usually associated with injuries to accompanying nerve trunks and may also be extensive to involve muscles, tendons and even bones and joints which go to increase the morbidity associated with these injuries.

Recognition of arterial injuries is of paramount importance if limbs and lives are to be preserved. Strict clinical criteria have to be adhered to in order to achieve this. The classical six P's of ischaemia: pain, pulselessness, pallor, paraesthesias, poikilothermia and paralysis if present go to reinforce the diagnosis but unfortunately may not be present in all cases especially in injuries to the axillary and brachial arteries where the radial pulse may be palpable ${ }^{7}$. In the North American literature, the clinical signs have usually been divided into 'hard' signs, which are definite indications of arterial injury and 'soft' signs, which may indicate arterial injury. ${ }^{3,4,8}$ 'Hard' signs are made up of distal circulatory deficit (ischaemia, diminished or absent pulse), bruit, expanding or pulsatile haematoma, and arterial bleeding. 'Soft signs' are however, made up of small or moderate sized stable haematomas, adjacent nerve injury, shock (unexplained by other injuries), and proximity of penetrating wound to major vascular structures. Injuries to peripheral arteries may be blunt resulting in multiple intimal tears, avulsion and transection of the arteries and are more likely to be associated with injuries to muscles, bones and joints. On the other hand injuries may be penetrating resulting in complete transection, partial transection, transfixion, linear tear, intimal tear or multiple lacerations.

Venous injuries usually accompany penetrating injuries to arteries and may result in arteriovenous fistulae if the initial injuries are missed or neglected. There may

\footnotetext{
${ }^{*}$ Author for correspondence

e-mail: $\underline{\text { h_k_aduful@yahoo.com }}$
} 
also be major injuries to veins without an accompanying arterial injury. Nerve injuries are also usually found when there is injury to neurovascular bundles it is therefore common to have injuries to nerves when the axillary or brachial arteries are injured.

Our aim was to examine the pattern of injuries to peripheral vessels in Ghana by looking at the mode of injury, pattern of referral, presentation and management of these injuries at the Korle-Bu Teaching Hospital, Accra.

\section{PATIENTS AND METHODS}

Patients in this analysis included all patients who were referred with vascular injuries and were treated by the two authors at the Korle-Bu Teaching Hospital, Accra between 1997 and 2005. Attention was paid to the mode of injury, the type of vessel injured, symptoms and signs at presentation, time elapsing before presentation, type of treatment given and morbidity and mortality following treatment. Routine full blood count (FBC), sickling test, and cross-matching of about two units of blood were requested for all the patients. Preoperative angiograms could only be performed on four patients, and two others had duplex scanning. The reason for the lack of radiological investigations for the other patients was due to financial constraints.

The operative procedure used in fresh injuries was a longitudinal incision to expose the injured artery and control bleeding followed by reconstruction. The procedure used in aneurysm and arterio-venous fistula operation was proximal and distal exposure of the injured arteries which were then controlled with vascular tapes and clamps followed by careful dissection to expose the aneurysm or arterio-venous fistula. Clean fresh injuries were either repaired by end to end anastomosis if the injuries were not over joints and primary repair would not be under tension.

In all cases of injuries overlying joints and in cases where tension to the anastomosis was likely and also in cases of false aneurysms and arteriovenous fistulae, repair was done with a reversed vein graft. Veins used were the long saphenous, the cephalic and the basilic veins. Arteries with good collaterals like the superficial temporal, inferior thyroid and the intercostal arteries were however, ligated. Veins were mainly treated by ligation but the major ones were treated with lateral suturing, and end to end anastomosis when transected. Patients with brachial and femoral artery injuries who were seen after six hours had fasciotomies after vascular reconstruction. Nerve injuries were repaired primarily with prolene $7 / 0$ or $6 / 0$.

\section{RESULTS}

There were fifty two (52) patients in the study. Forty seven (47) were males with age range 13-50 years. Five of the patients were females with age range of 3548 years. Types of vessels injured and modes of injury are shown in Table 1.

Table 1 Vessels injured and mode of injury

\begin{tabular}{|c|c|c|c|c|}
\hline & \multicolumn{4}{|c|}{ Aetiology } \\
\hline & $\begin{array}{l}\text { Pene- } \\
\text { trating }\end{array}$ & Blunt & $\begin{array}{l}\text { Iatro } \\
\text { genic }\end{array}$ & Total \\
\hline Brachial artery & 16 & 2 & 0 & 18 \\
\hline $\begin{array}{l}\text { Associated } \\
\text { vein }\end{array}$ & 9 & & & 9 \\
\hline Radial artery & 6 & 0 & 0 & 6 \\
\hline $\begin{array}{l}\text { Superficial } \\
\text { femoral artery }\end{array}$ & 10 & 0 & 0 & 10 \\
\hline $\begin{array}{l}\text { Associated } \\
\text { vein }\end{array}$ & 2 & & & 2 \\
\hline Popliteal artery & 5 & 3 & 0 & 8 \\
\hline Popliteal vein & 1 & & & 1 \\
\hline $\begin{array}{l}\text { Post tibial ar- } \\
\text { tery }\end{array}$ & 0 & 0 & 1 & 1 \\
\hline $\begin{array}{l}\text { Superficial } \\
\text { temporal artery }\end{array}$ & 1 & 0 & 0 & 1 \\
\hline $\begin{array}{l}\text { Inferior thyroid } \\
\text { artery }\end{array}$ & 1 & 0 & 0 & 1 \\
\hline $\begin{array}{l}1^{\text {st }} \text { intercostal } \\
\text { artery }\end{array}$ & 1 & 0 & 0 & 1 \\
\hline $\begin{array}{l}\text { Internal jugular } \\
\text { vein }\end{array}$ & 3 & 0 & 0 & 3 \\
\hline $\begin{array}{l}\text { Common iliac } \\
\text { vein }\end{array}$ & 0 & 1 & 0 & 1 \\
\hline $\begin{array}{ll}\text { Internal iliac } \\
\text { vein }\end{array}$ & 0 & 0 & 1 & 1 \\
\hline Axillary vein & & & 1 & 1 \\
\hline $\begin{array}{l}\text { Total } \\
(\%)\end{array}$ & $\begin{array}{l}43 \\
(82.7)\end{array}$ & $\begin{array}{l}6 \\
(11.5)\end{array}$ & $\begin{array}{l}3 \\
(5.8)\end{array}$ & $\begin{array}{l}52 \\
(100)\end{array}$ \\
\hline
\end{tabular}

Forty three patients (82.7\%) suffered penetrating injuries of which shotgun wounds sixteen patients (30.8\%), and stabbing and deep laceration from knives, broken glass and broken chainsaw fifteen patients (28.8\%) were the commonest. Injuries from road traffic accidents (RTA) were seen in seven patients (13.5\%) and injury from pieces of metal whilst chiselling accounted for $9.6 \%$ of the injuries. Iatrogenic injuries were mainly due to intra-operative injuries to the vessels.

Modes of presentation of vascular injuries are given in Table 2. Distal pulselessness, pulsatile bleeding and expansile haematoma were the commonest modes of presentation. 
Table 2 Mode of presentation of vascular injuries

\begin{tabular}{|l|l|l|}
\hline Presentation & $\begin{array}{l}\text { Number } \\
\text { N=52 }\end{array}$ & \% \\
\hline $\begin{array}{l}\text { Distal pulselessness or pulse } \\
\text { deficit }\end{array}$ & 26 & 50.0 \\
\hline Pulsatile bleeding or haematoma & 22 & 42.3 \\
\hline Pulsatile mass (false aneurysm) & 16 & 30.8 \\
\hline Neurological deficit & 13 & 25.0 \\
\hline Shock & 7 & 13.5 \\
\hline Cold ischaemic limb & 7 & 13.5 \\
\hline Haematoma & 7 & 13.5 \\
\hline Limb paralysis & 7 & 13.5 \\
\hline Arteriovenous fistula & 5 & 9.6 \\
\hline Gangrene & 2 & 3.8 \\
\hline Dyspnoea & 1 & 1.9 \\
\hline Haemoperitoneum & 1 & 1.9 \\
\hline
\end{tabular}

Associated injuries are given in Table 3. Twenty one (40.4\%) patients presented late sixteen (30.8\%) with complications of false aneurysms one of which had ruptured, and five (9.6\%) with arteriovenous fistulae. There were generally long delays in referral with a range of 1 hour to 4 years. Iatrogenic injuries were referred earlier within one hour to forty eight hours.

Most acute penetrating injuries were referred after twelve (12) hours. Blunt trauma patients presented twenty four (24) hours to two (2) weeks after injuries. Patients who presented with false aneurysms and arterio-venous fistulae following penetrating injuries were seen up to 4 years post injury.

Table 3 Associated injuries

\begin{tabular}{|l|l|l|}
\hline Tissue & Number & $\mathbf{\%}$ \\
\hline $\begin{array}{l}\text { Nerve injuries with defi- } \\
\text { cits }\end{array}$ & 13 & 25.0 \\
\hline Major muscle injury & 11 & 21.2 \\
\hline Bone injuries & 8 & 15.4 \\
$\begin{array}{l}\text { Humerus } \\
\text { Femur }\end{array}$ & 5 & \\
\hline Joint injury & 3 & \\
\hline Chest injury & 1 & 1.9 \\
\hline Trachea injury & 1 & 1.9 \\
\hline Parotid gland injury & 1 & 1.9 \\
\hline Head injury & 1 & 1.9 \\
\hline
\end{tabular}

Vascular investigations like angiograms and duplex scanning could be obtained for only thirteen (25.0\%) patients due to financial constraints. Four (7.7\%) patients required major lower limb amputation; these were made up of gangrene of the lower limb on presentation (2) and failed reconstruction of blunt superficial femoral, and popliteal artery injuries (2).
Four (7.7\%) patients died; two (2) from deep neck injuries involving the internal jugular vein and the trachea, one (1) from his original multiple injuries and one from disseminated intravascular coagulation, following ligation of iatrogenic laceration of the left internal iliac vein.

Forty four (84.6\%) patients were successfully treated by vascular reconstruction. Most of patients have been lost to further follow up after the first six to eight weeks of follow up. Four patients absconded from the ward due to their inability to settle their hospital bills and have been lost to follow up. Patients have been followed up for periods ranging from two weeks to one year.

\section{DISCUSSIONS}

Injuries to peripheral vessels have a potential to cause morbidity and mortality if they are not recognised and treated promptly. Strict criteria need to be followed to help make the diagnosis and hence help to avoid the incidence of complications of limb amputation, contractures and even death that characterise these injuries. The use of the classical six P's of ischaemia and the 'Hard and Soft' signs ${ }^{3,4,7}$ in the assessment of injuries to limbs will help to identify these injuries promptly to avoid complications. The high incidence of patients with vascular injuries who presented late with arteriovenous fistulae, false aneurysms and gangrene shows that there was failure of adherence to these protocols to diagnose these injuries by the first attending doctors. Most of the injuries seen were penetrating injuries and should therefore not have posed any diagnostic problems. In most centres, where vascular injuries are handled, preoperative radiological investigations for most injuries with hard signs may not be performed but are routinely performed when 'soft signs' are present. $^{3,4,7,9,10,11}$ Long term injuries with accompanying complications of arterio-venous fistula and false aneurysms are also routinely investigated with radiological studies including angiography and duplex scans. Most of the patients in this analysis did not however, have extensive radiological investigations on account of their inability to afford the cost of these investigations. It was possible to operate on these patients by the use of sound anatomical knowledge of the course of the injured vessels to obtain good results.

Early identification especially of injuries to major limb arteries and specification of the time of injury is also very important to help prevent the ischaemic reperfusion injury ${ }^{3,4}$ which may follow attempts at revascularisation when ischaemia has been going on for over six hours in femoral artery injuries and four hours in popliteal artery injuries. ${ }^{4}$ The survival of the limb may be improved by the presence of collaterals and this may 
explain why injuries to the popliteal artery which behaves like an end artery carry a worse prognosis compared to injuries to the femoral artery. The presence of collaterals alone may not be able to support the function of the limb in a lot of cases of arterial injury to major limb vessels.

Experiences from the Korean and Vietnamese conflicts in the 1950's and 1960's ${ }^{4}$ have shown that major vessels like the femoral, popliteal, axillary and brachial arteries are to be repaired compulsorily in the event of injuries to prevent limb loss or contractures. Other vessels like the radial and ulnar arteries of the upper limb and the posterior tibial, anterior tibial and the peroneal arteries of the lower limb can sometimes be ligated when transected since there are usually good anastomoses like the palmar or plantar arches between them. On the other hand if it is proven during the assessment of the patient that the blood flow in the collateral vessel using for example, the 'Allen Test' in the upper limb is not good enough, then the injured vessel needs to be repaired. ${ }^{3}$

Injuries to veins can usually be managed by the ligation of the involved vein but it is mandatory to repair injuries to major veins like the popliteal and the common femoral veins on account of the possibility of venous gangrene of the limb if these repairs are not carried out $^{3,4}$. Fasciotomies distal to the site of reconstruction is advised if the time of reconstruction of vascular injuries exceeds the four to six hours post injury because the muscles swell after revascularisation and may result in compartment syndrome.

Usually injuries to the vessels may be accompanied by injuries to nerves, bones and muscle. There may also be the tendency to confuse a combination of vascular and major nerve trunk injuries, as unsalvageable vascular injuries because of the presence of loss of sensation and paralysis that accompany these injuries. The application of a good history that properly documents the time of injury and a sound anatomical knowledge helps to prevent this confusion from arising.

The management of injuries to peripheral arteries can be adequately performed with reversed vein grafts using mainly the long saphenous, the cephalic and basilic veins as demonstrated in this analysis. The use of supported Polytetrafluoroethylene (PTFE) grafts gives a comparable long term patency rate to the reversed veins but carries the disadvantage of cost.

\section{CONCLUSION}

We conclude that injuries to peripheral vessels seen in our environment are mainly due to penetrating injuries. Some of these injuries are unfortunately missed due to poor knowledge of the symptoms and signs of these injuries by the initial attending medical personnel. The injuries can however, be adequately treated by reconstruction without the recourse to sophisticated and expensive investigations and treatment modalities.

\section{REFERENCES}

1. Degiannis E., Velhamos, G., Krawczykowski D., Levy R.D., Souter I., Saadia R. Penetrating injuries of the subclavian vessels. Br. Journal of Surgery 1994; 81, 524-526

2. Degiannis E., Levy R.D., Velhamos G.C., Potokar T., Saadia R. Penetrating injuries of the femoral artery. Br. Journal of Surgery 1995, 82. 492-495

3. Rutherford R.B, Vascular Surgery. W.B Saunders 1995. p713-735

4. Callow A.D, Ernst C.B. Vascular Surgery Theory and Practice. Appleton and Lange 1995. p 9851037

5. Golledge J., Fligestone L.J., Scriven M.W., Lane I.F. Vascular Trauma in civilian practice. Ann $R$ Coll Surg Engl 1995;77:417-420

6. Lewis D.R., Bullbulia R.A., Murphy P., Jones A.J., Smith F.C.T., Baird R.N., Lamont P.M. Vascular surgical intervention for complications of cardiovascular radiology: 13 years' experience in a single centre. Ann R Coll Surg Engl 1999; 81: 2326.

7. Hunt C.A., Kingsley J.R. Vascular injuries of the upper extremity. South Med J 2000; 93(5): 466468

8. Adebo O. Limb salvage in periperal Vascular Trauma. West African Journal of Surgery. 1996; 15(3) 139-142.

9. Bynoe RP, Miles WS, Bell RM, Greenwold DR, Sessions G, Haynes JL, Rush DS, Noninvasive diagnosis of vascular trauma by duplex ultrasonography. Journal of Vascular Surgery. 199;14(3):346-52,

10. Bergstein JM. Blair JF. Edwards J. Towne JB. Wittmann DH. Aprahamian C. Quebbeman EJ. Pitfalls in the use of color-flow duplex ultrasound for screening of suspected arterial injuries in penetrated extremities. Journal of Trauma-Injury Infection \& Critical Care. 1992;33(3):395-402,

11. McCormick TM. Burch BH, Routine angiographic evaluation of neck and extremity injuries. Journal of Trauma-Injury Infection \& Critical Care. 1979;19(5):384-7 